surement precisions (0.5\%) (20) in the travel times themselves.

20. Single-crystal samples of $\mathrm{MgO}$ (purity $>99.9 \%$ ) were oriented with $\mathrm{x}$-ray diffraction method described in (13) to [100] and [110] orientations (better than $1^{\circ}$ ); the samples were cored, cut, and polished to cylinders of about $1.8 \mathrm{~mm}$ in diameter and 1.2 to $1.5 \mathrm{~mm}$ in length. The original sample lengths were measured to micrometers, that is, $\pm 1 \mu \mathrm{m}$. Measurements of the sample travel time were achieved by overlapping the glass buffer rod echo and the sample echo and recording the amplitudes of the interference signal as a function of the frequency (from 20 to $70 \mathrm{MHz}$ ). Precision in the travel time measurements is about $2 \mathrm{~ns}$ or $0.5 \%$ for the sample used in this study. We used $\mathrm{Pt}$ (20 $\mu \mathrm{m}$ thick) and Au ( $2 \mu \mathrm{m}$ thick) foils to couple the acoustic wave from the glass buffer rod to the sample. These metal foils alleviate the problems of the compressibility and thermal expansivity mismatches between the buffer and the sample, but they also introduce uncertainties in the acoustic travel time [(25); I. Jackson, H. Niesler, D. J. Weidner, J. Geophys. Res. 86, 3736 (1981)]. Their effect on the travel times is calculated and removed with the algorithm detailed in (25). Redundant experiments were also performed with $\mathrm{Pt}$ foil and Au foil for the same elastic mode $\left(\mathrm{C}_{44}\right)$; after correcting for the effect of the bonds (Pt or Au foils), the sample travel times agree within the measurement uncertainties (2 ns).

21. In extracting the cross pressure-temperature derivatives of the elastic moduli $\left(\partial^{2} \mathrm{C} . / \partial P \partial T\right)$, our modulus data at elevated $P$ and $T$ are fit by polynomials $\left[C_{i j}=\right.$ $\left.C_{i j}{ }^{\circ}+\left(\partial C_{i j} / \partial P\right) P+\left(\partial C_{i j} / \partial T\right) T+\left(\partial^{2} C_{i j} / \partial P \partial T\right) P T\right]$ with the constraints of fixing the pressure derivatives $\left(\partial C_{i j} / \partial P\right)$ at ambient temperature (from our high pressure-ambient temperature data) and the temperature derivatives $\left(\partial C_{i j} / \partial T\right)$ at ambient pressure [from averaging the rectangular parallelopiped resonance (RPR) data (5)]. Such fits are mathematically robust because the boundary conditions (along the pressure and temperature axes) are well defined: the RPR method provides data if very high precision along the temperature axis, and the acoustic data along the pressure axis also have high precision [in light of their good agreement with the results obtained from the gas pressure vessel (Fig. 3)].

22. D. G. Isaak and E. K. Graham, J. Geophys. Res. 81 , 2483 (1976); G. Chen, A. Yoneda, I. C. Getting, H. A. Spetzler, ibid. 101, 25 (1996).

23. D. G. Isaak, Phys. Earth Planet. Inter. 80, 37 (1993).

24. T. S. Duffy, R. J. Hemly, H. K. Mao, Phys. Rev. Lett. 74, 1371 (1995).
25. H. A. Spetzler, G. Chen, S. Whitehead, I. C. Getting, Pure Appl. Geophys. 141, 341 (1993).

26. This work was carried out with the X17B1 beamline of the National Synchrotron Light Source (NSLS) of the Brookhaven National Laboratory. Y. Sinelnikov helped in carrying out the experiments. We thank all of the personnel who contributed to the execution of these ultrasonic experiments; J. B. Hastings and D. P. Siddons (NSLS) for their technical supports at the beamline; C. Koleda, P. Hoversen, H. Schay, B. Huebsch, B. Vitale, and K. Baldwin (SUNY, Stony Brook) for their support in machining cell parts and maintanence of the high-pressure and high-temperature apparatus; J. Chen and M. Vaughan (SUNY, Stony Brook) of the SAM85 operational team for their support in this new project; and Y. Wang (Consortium for Advanced Radiation Sources, Chicago) for valuable suggestions on designing the cell assembly. These high-pressure experiments were conducted with the joint support of SUNY and the NSF Science and Technology Center for High Pressure Research (CHiPR) under grant EAR89-20239 and by NSF grants to R.C.L. (EAR93-04502 and 96-14612). This is Mineral Physics Institute publication number 230.

2 March 1998; accepted 12 May 1998

\title{
The Influence of Vegetation-Atmosphere- Ocean Interaction on Climate During the Mid-Holocene
}

\author{
Andrey Ganopolski, Claudia Kubatzki, ${ }^{*}$ Martin Claussen, \\ Victor Brovkin, Vladimir Petoukhov
}

Simulations with a synchronously coupled atmosphere-ocean-vegetation model show that changes in vegetation cover during the mid-Holocene, some 6000 years ago, modify and amplify the climate system response to an enhanced seasonal cycle of solar insolation in the Northern Hemisphere both directly (primarily through the changes in surface albedo) and indirectly (through changes in oceanic temperature, sea-ice cover, and oceanic circulation). The model results indicate strong synergistic effects of changes in vegetation cover, ocean temperature, and sea ice at boreal latitudes, but in the subtropics, the atmosphere-vegetation feedback is most important. Moreover, a reduction of the thermohaline circulation in the Atlantic Ocean leads to a warming of the Southern Hemisphere.

Numerous paleodata suggest that the climate of the mid-Holocene around 6 thousand years ago (ka) was quite different from that of today. Generally, the summer in many mid- to high-latitude regions of the Northern Hemisphere was warmer, and paleobotanic data indicate an expansion of boreal forests north of the modern tree line (1-6). In North Africa, paleoclimatological reconstructions $(5,7,8)$ reveal a climate

A. Ganopolski, C. Kubatzki, V. Brovkin, Potsdam-Institut für Klimafolgenforschung, Postfach 601203, D-14412 Potsdam, Germany.

M. Claussen, Potsdam-Institut für Klimafolgenforschung, Postfach 601203, D-14412 Potsdam, Germany and Institut für Meteorologie, FU Berlin, C.-H. Becker Weg 6-10, D-12165 Berlin, Germany.

V. Petoukhov, Potsdam-Institut für Klimafolgenforschung, Postfach 601203, D-14412 Potsdam, Germany and Oboukhov Institute for Atmospheric Physics, Pyzhevsky 3, 109017 Moscow, Russia.

*To whom correspondence should be addressed. E-mail: kubi@pik-potsdam.de wetter than today's. Moreover, it has been found $(9,10)$ that vegetation covered a substantial part of the Sahara during the mid-Holocene. Climate models have been used to examine how the changes in Earth's orbit result in the differences between the climate of today and that of $6 \mathrm{ka}$. Atmosphere models that use prescribed modern sea surface temperatures (SSTs), sea-ice distribution, and vegetation cover (11-14) seem to underestimate the amplitude of the observed climatic differences $(2,5)$. Sensitivity studies in which artificially prescribed changes in vegetation were introduced into climate models $(2,15,16)$ suggest that positive feedbacks between climate and vegetation can be important in explaining the climate changes during the Holocene. Coupled atmosphere-vegetation models $(17,18)$ support this hypothesis. Recently, coupled atmosphere-ocean models $(19,20)$ demonstrated that some of the climatic differences might be explained by changes in ocean temperatures, but again, the simulations reveal only partial agreement with paleodata. We describe the strong synergistic effect of the response of atmosphere, ocean, and vegetation on the changed solar insolation conditions found in our coupled atmosphere-ocean-vegetation model.

We used a climate system model of intermediate complexity, CLIMBER (for CLIMate and BiosphERe) $(21,22)$, to perform a set of consistent experiments with different model configurations from the atmosphereonly model to the coupled atmosphereocean-terrestrial vegetation model. CLIMBER does not employ any flux adjustment between the atmospheric and oceanic modules. The model has a coarse resolution of $10^{\circ}$ in latitude and $51^{\circ}$ in longitude. It encompasses a 2.5-dimensional dynamical-statistical atmosphere model; a multibasin, zonally averaged ocean model, including sea ice; and a terrestrial vegetation model (23). The latter simulates vegetation that is in equilibrium with climate. Vegetation cover is represented as a mixture of trees, grass, and desert (bare soil). The fraction of each is not a discrete, but a continuous function of growing degree days (sum of mean daily temperature for days with temperature above $0^{\circ} \mathrm{C}$ ) and annual precipitation. Hence, in contrast to biome-type models, CLIMBER is able to describe changes in vegetation cover that can be interpreted as shifts in vegetation zones smaller than the spatial resolution of the model.

A control run was performed, using the fully coupled atmosphere-ocean-biosphere version of the model for characteristics of preindustrial climate (when the system was close to equilibrium) - in other words, modern solar insolation and a $\mathrm{CO}_{2}$ concentra- 
Fig. 1. Zonally averaged differences in near-surface air temperature over land (in ${ }^{\circ} \mathrm{C}$ ) between our four mid-Holocene simulations and the presentday control run for boreal summer (June, July, August) (A) and boreal winter (December, January, February) (B). The solid line indicates differences between simulation A (atmosphere-only model) and control; the shortdashed line refers to simulation AO (atmosphereocean model) minus control; the long-dashed line refers to simulation AV (atmosphere-vegetation
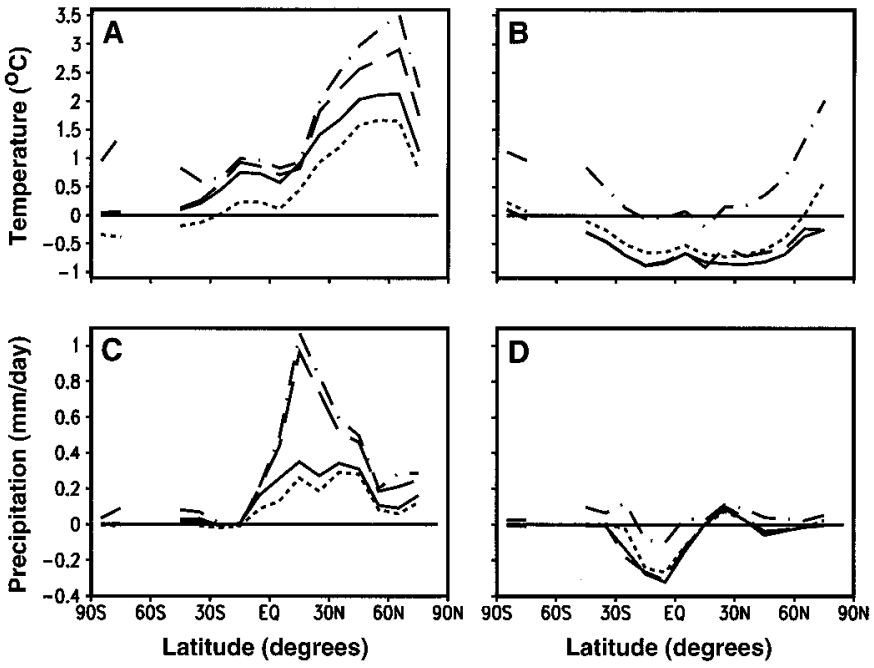

model) minus control; and the dot-dashed line refers to simulation AOV (atmosphere-ocean-vegetation model) minus control. (C and $\mathbf{D}$ ) are the same as (A) and (B), respectively, but for precipitation (in mm/day). All results are averages over the last 100 years of a simulation.

tion of $280 \mathrm{ppm}$. To attain equilibrium, the control simulation (as well as each of the following experiments) was integrated for 3000 years. The model performs reasonably well for modern climate $(21,22)$. Its equilibrium and transient response to changes in $\mathrm{CO}_{2}$ concentration are similar to those of coupled general circulation models (GCMs). For example, the sensitivity to a doubling of $\mathrm{CO}_{2}$ is $3.0^{\circ} \mathrm{C}$. Simulated vegetation cover agrees well with the main features of global vegetation distribution. In particular, the belts of boreal and tropical rain forest, as well as the areas of subtropical desert, are represented realistically in the model.
A
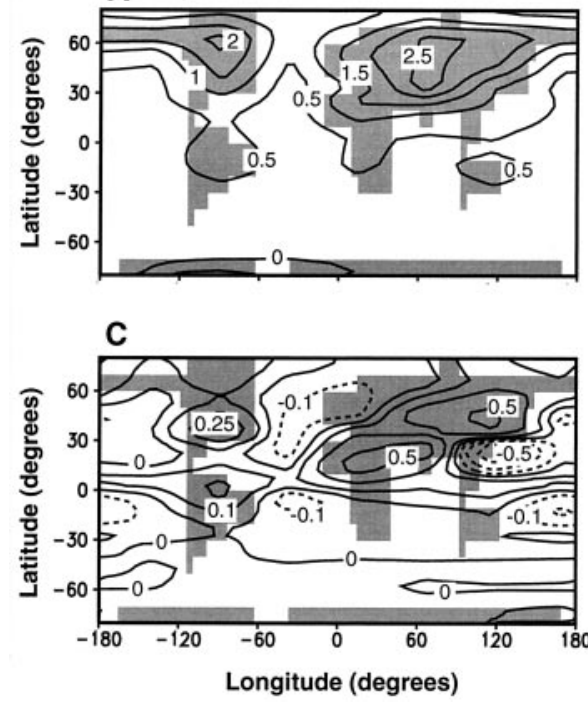

We performed four simulations for the mid-Holocene, using different model configurations. Orbital parameters were set to midHolocene values (24), resulting in an enhanced seasonal cycle of solar insolation in the Northern Hemisphere. The $\mathrm{CO}_{2}$ concentration was the same as in the control run. Simulation A was undertaken using the atmosphere-only model. Thus, the model configuration was almost identical with other model studies (11-14), with the exception that we prescribed SSTs, sea-ice characteristics, and vegetation cover from the results of the control run rather than from empirical data. This allowed results of our mid-Holo-
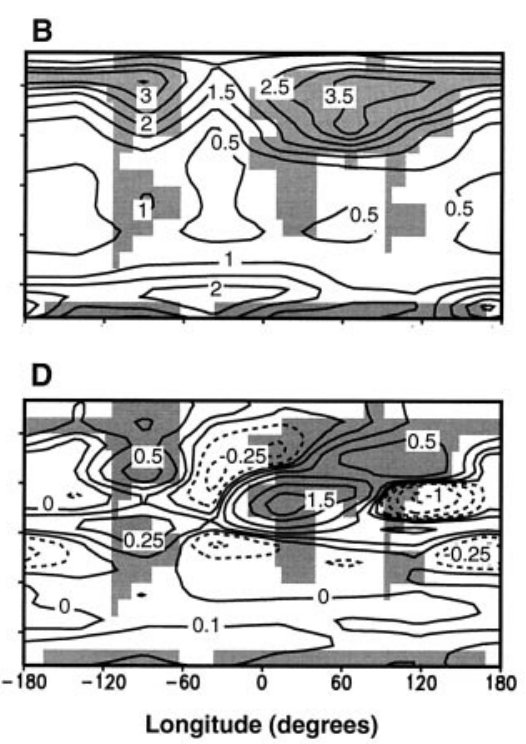

Fig. 2. Differences in near-surface air temperature (in ${ }^{\circ} \mathrm{C}$ ) during boreal summer between two of our four mid-Holocene simulations and the present-day control run. (A) Simulation A minus control. (B) Simulation AOV minus control. (C and $\mathbf{D})$ are the same as $(A)$ and $(B)$, respectively, but for precipitation (in $\mathrm{mm} /$ day). Dashed lines indicate negative differences.
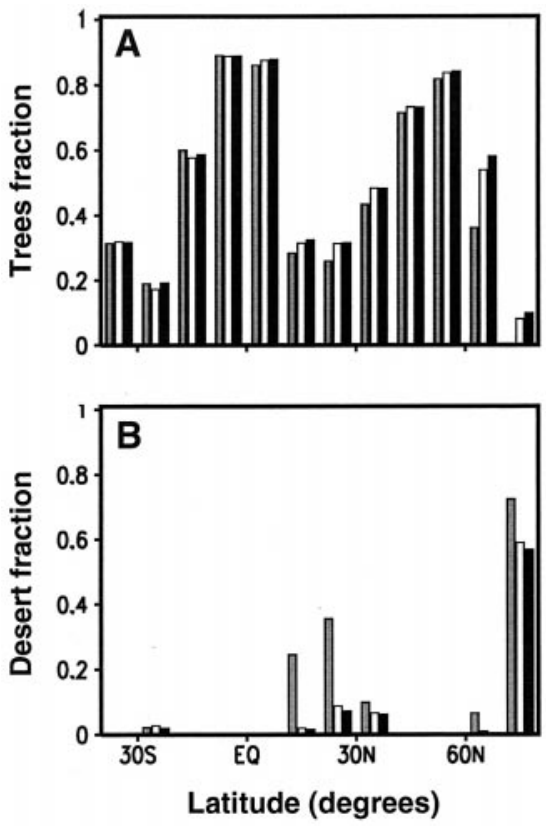

Fig. 3. Zonally averaged trees fraction (A) and desert fraction (B) for the control run (gray), simulation AV (white), and simulation AOV (black).

cene runs to be compared directly with the control run. In simulation $\mathrm{AO}$, we employed the coupled atmosphere-ocean model, and vegetation cover was fixed as in simulation A. Simulation AV was run with interactive vegetation, while ocean characteristics were fixed as in simulation A. Finally, in simulation AOV, we used the fully coupled atmosphere-ocean-vegetation model as in the control run.

In response to mid-Holocene insolation changes, the atmosphere-only model (simulation A) showed warming over the continents of the Northern Hemisphere in summer exceeding $+2.5^{\circ} \mathrm{C}$ and cooling in winter and spring exceeding $-1.5^{\circ} \mathrm{C}$ compared to temperatures in the control run (Fig. 1, A and B; Fig. 2A; Table 1). This is in agreement with results of many atmospheric GCM simulations $(11-14,18,25)$. A global annual increase of precipitation is mainly caused by the intensification of Northern Hemisphere summer monsoon in North Africa, South Asia, and East Asia (Fig. 2C). Earlier studies $(11-14,18,25$, 26) also revealed the strongest increase in precipitation in the African and South Asian monsoon regions. Changes in the Southern Hemisphere are generally smaller because of fixed SSTs.

The results of simulation $\mathrm{AO}$ are, in general, similar to those of simulation A. However, the thermal inertia of the ocean leads to a slight damping of the direct atmospheric response to the insolation changes (Fig. 1). At high northern latitudes, increased summer insolation causes a reduction of sea ice 
(Table 1), which due to albedo feedback leads to a warming of the Arctic throughout most of the year. In the tropics, SST anomalies in the range of $-0.5^{\circ} \mathrm{C}$ to $+0.3^{\circ} \mathrm{C}$ lag behind the solar insolation anomalies by about 2 months. Maximum cooling (warming) there is reached in April/May (October), leading to reduced (increased) precipitation over tropical oceans in agreement with results of the coupled GCM described in (20). In the tropics, CLIMBER also showed an increase of upward velocity over continents in spring and a northward shift of the Intertropical Convergency Zone in autumn similar to (20). However, in contrast to (20), an increase in precipitation in North Africa and Southeast Asia (compared to simulation A with fixed SSTs) could not be detected in CLIMBER. Substantial changes in oceanic circulation compared to the control simulation were not found.

Simulation AV revealed pronounced changes in the vegetation cover in northern high latitudes and the subtropics (Fig. 3). Owing to warmer summers and longer growing seasons in the Northern Hemisphere, forests expand farther northward. Because of the albedo feedback, this amplifies the temperature rise (Fig. 1, A and $\mathrm{B}$; Table 1). The area of tundra and polar desert decreases by some $3 \times 10^{6} \mathrm{~km}^{2}$, which is comparable with results of the coupled atmosphere-biome model described in (18), where a decrease of tundra and polar desert of some $2 \times 10^{6} \mathrm{~km}^{2}$ can be deduced. In the subtropics, the precipitation increase at $6 \mathrm{ka}$ simulated by CLIMBER resulted in an extension of vegetation (at the expense of desert areas, Fig. 3B), which in turn strengthened precipitation owing to stronger African and Asian summer monsoons (Fig. 1C) similar to (17). In North Africa $\left(10^{\circ}\right.$ to $\left.30^{\circ} \mathrm{N}\right)$, the resulting desert fraction was $14 \%$ in comparison to $71 \%$ in the control run. A greening of the Sahara was also obtained with the coupled atmosphere-biome models described in $(17,18)$, although they show disagreement in the amplitude of their climate and vegetation response in this region.

Results of the three experiments $\mathrm{A}, \mathrm{AO}$, and AV show that the responses of CLIMBER to changes in orbital parameters are comparable with those obtained using more sophisticated and high-resolution models when performed in similar configuration. Together with the successful simulations of the modern and last-glacial-maximum climates (21), this gives more credibility to our model results.

Finally, the results of simulation AOV demonstrate a strong synergism between climate subsystems. Unlike the previous three simulations, AOV revealed pronounced annual warming in both hemispheres (Fig. 1, A and B). In the Northern Hemisphere, temperature increased by about $1^{\circ} \mathrm{C}$ both in summer and winter compared to simulation $\mathrm{AO}$ (Table 1). Thus, winter became warmer compared to the control simulation in spite of lower solar insolation (and in contrast to simulations $\mathrm{A}, \mathrm{AO}, \mathrm{AV})$. The warming is caused by a decrease of planetary albedo due to an extension of the boreal forests and a decrease of subtropical deserts. In high northern latitudes, warming was strongly amplified by the sea-ice albedo feedback. The annual amount of sea ice decreased by one-quarter

Table 1. Differences from the present-day control run of our four mid-Holocene simulations (Sim.; $A$, $\mathrm{AO}, \mathrm{AV}, \mathrm{AOV}$ ) for boreal summer (June, July, August) and winter (December, January, February) and annual averaged near-surface air temperature (Temp., $\left.{ }^{\circ} \mathrm{C}\right)$, precipitation (Prec., $\mathrm{mm} /$ day), and sea-ice area [lce, $10^{6} \mathrm{~km}^{2}$ with fractions (\%) of present-day sea-ice area in parentheses]. $\mathrm{NH}$ indicates values on average over the Northern Hemisphere, SH over the Southern Hemisphere, and N-AFR over North Africa (between $10^{\circ}$ and $30^{\circ} \mathrm{N}$ ). The index $\mathrm{L}$ refers to averages over land areas only.

\begin{tabular}{|c|c|c|c|c|c|c|c|c|}
\hline \multirow{2}{*}{ Sim. } & \multicolumn{3}{|c|}{ Temp. $\left({ }^{\circ} \mathrm{C}\right)$} & \multicolumn{3}{|c|}{ Prec. (mm/day) } & \multicolumn{2}{|c|}{$\begin{array}{c}\text { Ice } \\
{\left[10^{6} \mathrm{~km}^{2}(\%)\right]}\end{array}$} \\
\hline & $\mathrm{NH}_{\mathrm{L}}$ & $\mathrm{NH}$ & $\mathrm{SH}$ & $\mathrm{NH}_{\mathrm{L}}$ & $\mathrm{SH}_{\mathrm{L}}$ & $N-A F R_{L}$ & $\mathrm{NH}$ & $\mathrm{SH}$ \\
\hline \multicolumn{9}{|c|}{ Boreal summer } \\
\hline$A$ & 1.7 & 1.0 & 0.2 & 0.25 & 0.04 & 0.58 & - & - \\
\hline $\mathrm{AO}$ & 1.2 & 0.6 & -0.2 & 0.19 & 0.01 & 0.52 & $-0.9(-9.7)$ & $0.8(4.9)$ \\
\hline AV & 2.2 & 1.3 & 0.3 & 0.49 & 0.06 & 1.67 & - & - \\
\hline AOV & \multirow{2}{*}{\multicolumn{8}{|c|}{ Boreal winter }} \\
\hline & & & & & & & & \\
\hline A & -0.8 & -0.5 & -0.3 & -0.01 & -0.17 & -0.01 & - & - \\
\hline $\mathrm{AO}$ & -0.5 & -0.3 & -0.2 & -0.01 & -0.13 & 0 & $-0.7(-5.9)$ & $-0.3(-4.0)$ \\
\hline AV & -0.7 & -0.4 & -0.3 & 0 & -0.17 & 0.02 & - & - \\
\hline AOV & 0.4 & 0.6 & 0.5 & $\begin{array}{c}0.05 \\
\text { Ant }\end{array}$ & $\begin{array}{l}-0.01 \\
\text { al averas }\end{array}$ & 0.05 & $-1.8(-15.7)$ & $-1.9(-26.2)$ \\
\hline A & 0.2 & 0.1 & 0 & 0.08 & -0.03 & 0.18 & - & - \\
\hline $\mathrm{AO}$ & 0.1 & 0 & -0.1 & 0.06 & -0.03 & 0.16 & $-0.9(-8.4)$ & $0.4(3.0)$ \\
\hline AV & 0.5 & 0.3 & 0.1 & 0.19 & -0.03 & 0.63 & - & - \\
\hline AOV & 1.2 & 1.0 & 0.7 & 0.26 & 0.06 & 0.72 & $-2.4(-22.6)$ & $-2.1(-17.3)$ \\
\hline
\end{tabular}

compared to the control simulation (Table 1). As a result, the ocean absorbs more heat in summer and releases it into the atmosphere in autumn and winter. Thus, results of simulation AOV agree much better than the previous three with the paleodata, indicating a summer temperature of up to $4^{\circ} \mathrm{C}$ and a winter temperature of up to $3^{\circ} \mathrm{C}$ higher than for today's climate in the northern parts of Europe, Asia, and North America (1-5). Boreal forest areas increase further (compared to simulation AV, Fig. 3A) at the expense of tundra and polar desert. These changes in the boreal forest area can be interpreted (assuming that changes in the trees fraction represent a meridional shift of the border between taiga and tundra) as an averaged northward shift of the tree line by about $250 \mathrm{~km}$. This agrees with pollen estimations, which indicate a northward forest expansion during the mid-Holocene by 50 to $300 \mathrm{~km}(2,3)$. In the subtropics, the desert area further shrinks (compared to simulation AV, Fig. 3B). The resulting increase of annual precipitation in North Africa is four times larger than for simulation A (Table 1).

The warming of the Southern Hemisphere in simulation AOV is caused primarily by a reduction of the Atlantic thermohaline circulation. It became weaker and more shallow (Fig. 4), whereas Antarctic bottom
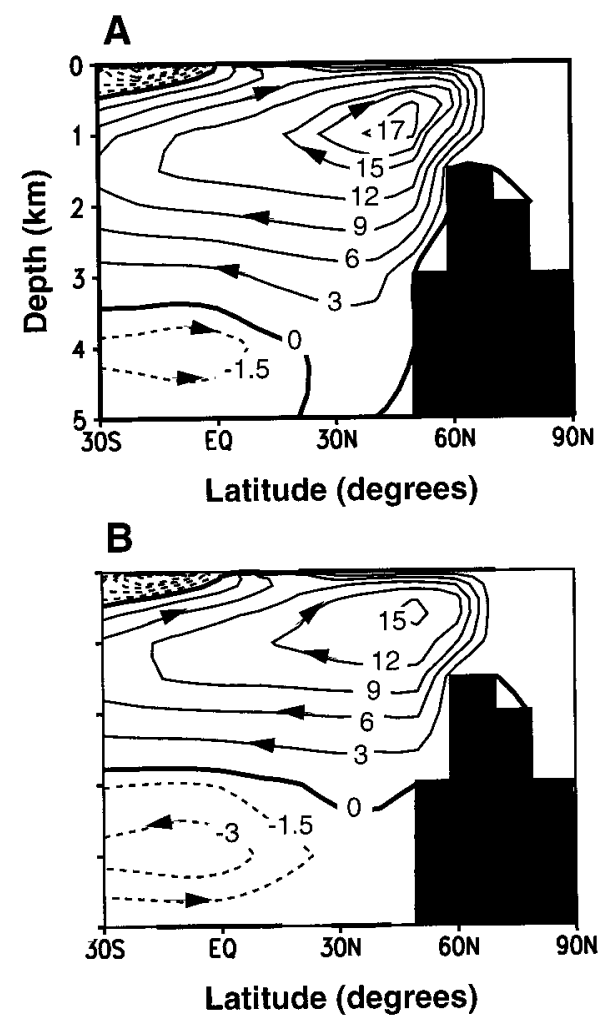

Fig. 4. Meridional transport stream function (in $\mathrm{Sv}=10^{6} \mathrm{~m}^{3} / \mathrm{s}$ ) in the Atlantic for the control run (A) and for simulation AOV (B). Black boxes indicate ocean topography. 
water penetrated further north. The reduction of thermohaline circulation was caused by a warming and freshening of the North Atlantic and Arctic. This led to a decrease of North Atlantic deep water density and a reduction of the density gradient between the North and South Atlantic, which controls the intensity of meridional overturning (27). While the warming of the North Atlantic is the result of nonlinear interaction between vegetation-albedo and sea ice-albedo feedbacks, as discussed above, the freshening of the North Atlantic is a consequence of an intensification of the hydrological cycle in the Northern Hemisphere and an increase in runoff from the continents, which enhances the freshwater flux into the North Atlantic by $0.05 \mathrm{~Sv}$. Because of the weakening of thermohaline circulation, up to 0.1 PW less heat is transported from the South to the North Atlantic, which produces a negative feedback for the Northern Hemisphere warming, but raises the Southern Hemisphere temperature by $0.7^{\circ} \mathrm{C}$ in the annual mean. The warming reached maximum values of more than $2^{\circ} \mathrm{C}$ near the Antarctic (Fig. 2B), due to an amplification of temperature changes caused by a reduction of the area of sea ice (Table 1). Paleodata $(28,29)$ support the possibility of an Antarctic and southern ocean during the mid-Holocene that was up to $2^{\circ} \mathrm{C}$ warmer than at present.

Our results suggest that during the midHolocene, the following three regions were strongly affected by processes related to changes in the vegetation structure and in the oceans. (i) High northern latitudes: A northward expansion of boreal forest due to summer warming leads to an annual warming via the vegetation-snow-albedo feedback, strongly amplified by the sea ice-albedo feedback. (ii) Subtropics: Strong positive feedback between vegetation and precipitation in the subtropics leads to a greening of the Sahara. Major precipitation changes are due to interactive vegetation, while the role of changes in oceanic temperature is ambiguous. (iii) Atlantic: Strong warming of the North Atlantic, together with an increased freshwater flux into the Atlantic basin, leads to a weakening of the thermohaline circulation, which in turn results in a warming of the Southern Hemisphere.

In conclusion, our results reveal strong synergistic effects between the different climate subsystems. They also offer an explanation of how vegetation changes may promote changes in the ocean circulation, thereby leading to a global response connecting both hemispheres. Our results, by and large, agree with paleoclimatic reconstructions. Results from this rather coarsescale climate-system model provide guid- ance in the interpretation of past climates. Simulations using comprehensive climate system models in combination with analysis of paleodata are needed to obtain more detailed pictures of the paleoclimate.

\section{REFERENCES AND NOTES}

1. T. Webb III, P. J. Bartlein, S. P. Harrison, K. H. Anderson, Global Climates Since the Last Glacial Maximum, H. E. Wright et al., Eds. (Univ. of Minnesota Press, Minneapolis, MN, 1993), chap. 17

2. TEMPO Members, Global Biogeochem. Cycles 10 , 727 (1996).

3. I. C. Prentice, J. Guiot, B. Huntley, D. Jolly, R. Cheddadi, Clim. Dyn. 12, 185 (1996).

4. R. Cheddadi, G. Yu, S. P. Harrison, I. C. Prentice, ibid. 13, 1 (1997).

5. V. A. Klimanov and A. A. Velichko, Atlas of Paleoclimates and Paleoenvironments of the Northern Hemisphere. Late Pleistocene-Holocene, B. Frenzel, M. Pesci, A. A. Velichko, Eds. (Gustav Fischer, Stuttgart, Germany, 1992)

6. R. A. Monserud, O. V. Denissenko, N. M. Tchebakova, Clim. Res. 3, 143 (1993).

7. G. Yu and S. P. Harrison, Clim. Dyn. 12, 723 (1996).

8. F. A. Street and A. T. Grove, Quat. Res. 12, 83 (1979).

9. D. Jolly, S. P. Harrison, B. Damnati, R. Bonnefille, Quat. Sci. Rev., in press.

10. P. Hoelzmann et al., Global Biogeochem. Cycles 12 , 35 (1998)

11. N. de Noblet, P. Braconnot, S. Joussaume, V. Masson, Clim. Dyn. 12, 589 (1996).
12. C. D. Hewitt and J. F. B. Mitchell, J. Clim. 9, 3505 (1996)

13. S. Lorenz, B. Grieger, P. Helbig, K. Herterich, Geol. Rundsch. 85, 513 (1996).

14. N. M. J. Hall and P. J. Valdes, J. Clim. 10, 3 (1997)

15. J. A. Foley, J. E. Kutzbach, M. T. Coe, S. Levis, Nature 371, 52 (1994).

16. J. E. Kutzbach, G. Bonan, J. A. Foley, S. P. Harrison, ibid. 384, 623 (1996).

17. M. Claussen and V. Gayler, Global Ecol. Biogeogr. Lett. 6, 369 (1997)

18. D. Texier et al., Clim. Dyn. 13, 865 (1997).

19. J. E. Kutzbach and Z. Liu, Science 278, 440 (1997)

20. C. D. Hewitt and F. B. Mitchell, Geophys. Res. Lett. 25, 361 (1998).

21. A. Ganopolski, S. Rahmstorf, V. Petoukhov, M Claussen, Nature 391, 351 (1998).

22. V. Petoukhov et al., PIK Rep. No. 35 (PotsdamInstitut für Klimafolgenforschung, Potsdam, Germany, 1998).

23. V. Brovkin, A. Ganopolski, Y. Svirezhev, Ecol. Model. 101, 251 (1997)

24. A. L. Berger, J. Atmos. Sci. 35, 2362 (1978).

25. COHMAP Members, Science 241, 1043 (1988).

26. M. T. Coe and G. B. Bonan, J. Geophys. Res. 102 11087 (1997).

27. S. Rahmstorf, Clim. Dyn. 12, 799 (1996).

28. J. Jouzel et al., Nature 329, 403 (1987).

29. J. D. Hays, J. Imbrie, N. J. Shackleton, Science 194 1121 (1976)

30. We thank S. Rahmstorf, Potsdam-Institut für Klimafolgenforschung (PIK), and the anonymous reviewers for constructive comments, and A. Schlums, PIK, for editing our manuscript.

11 March 1998; accepted 12 May 1998

\title{
Planar Patterned Magnetic Media Obtained by lon Irradiation
}

\author{
C. Chappert, H. Bernas, J. Ferré, V. Kottler, J.-P. Jamet, \\ Y. Chen, E. Cambril, T. Devolder, F. Rousseaux, \\ V. Mathet, H. Launois
}

By ion irradiation through a lithographically made resist mask, the magnetic properties of cobalt-platinum simple sandwiches and multilayers were patterned without affecting their roughness and optical properties. This was demonstrated on arrays of 1-micrometer lines by near- and far-field magnetooptical microscopy. The coercive force and magnetic anisotropy of the irradiated regions can be accurately controlled by the irradiation fluence. If combined with high-resolution lithography, this technique holds promise for ultrahigh-density magnetic recording applications.

A mong the methods proposed to increase
the data storage density in magnetic record-
ing media well beyond expected limits ( 1 ,

C. Chappert, V. Kottler, T. Devolder, V. Mathet, Institut d'Electronique Fondamentale, Unité de Recherche Associée CNRS 022, Université Paris Sud, 91405 Orsay Cedex, France.

H. Bernas, Centre de Spectrométrie Nucléaire et de Spectrométrie de Masse, Unité Propre de Recherche CNRS 6412, Université Paris Sud, 91405 Orsay Cedex France.

J. Ferré and J.-P. Jamet, Laboratoire de Physique des Solides, Unité de Recherche Associée CNRS 02, Université Paris Sud, 91405 Orsay Cedex, France.

V. Kottler, Y. Chen, E. Cambril, F. Rousseaux, H. Launois, Laboratoire de Microstructures et de Microélectronique, Unité Propre de Recherche CNRS 020, 196 Avenue H. Ravera, BP 107, 92225 Bagneux Cedex, France.
$2)$, media patterning $(3,4)$ by appropriate nanometer scale techniques (5-8) is particularly attractive. The latter will also be required in the field of magnetoelectronics (9), with potential applications for new magnetic submicron devices: read head, memory cells, and so forth. To implement a patterning technique, however, several major problems must be solved. First, the patterning process should allow control of the magnetization reversal properties of the submicron element that constitutes the bit or the sensor. Second, medium planarity is crucial. This is related, for instance, to the nanometer scale head-to-media clearance in present day hard-disk technology [as well 